\title{
A Novel Ultra-Large Flat Plate Heat Pipe Manufactured by Thermal Spray
}

\author{
C. Feng ${ }^{\mathrm{a}, 1,}$,, M. Gibbons ${ }^{\mathrm{a}, 1}$, M. Marengo ${ }^{\mathrm{b}}, \mathrm{S}$. Chandra $^{\mathrm{a}}$ \\ ${ }^{\text {a }}$ Centre for Advanced Coating Technologies, University of Toronto, Toronto, ON M5S 3G8, Canada. \\ ${ }^{\mathrm{b}}$ School of Computing, Engineering and Mathematics, University of Brighton, BN2 4GJ Brighton, U.K.
}

\begin{abstract}
An ultra-large flat plate copper heat pipe $\left(180 \times 180 \mathrm{~mm}^{2}\right)$ was constructed using a thermal spray technique, and it was then thermally characterized. A porous copper wick was fabricated by using a flame spray torch to deposit a mixture of copper and aluminum particles onto the target substrate. A stainless-steel wire mesh acts as a mask so that the coating deposited is in the form of an array of microstructures with channels between them. After spraying, the aluminum deposit is leached away by immersing the plate in a dilute $\mathrm{NaOH}$ solution to produce a porous structure. A second copper plate was placed on top of the coated surface, and their edges were vacuum brazed to form a sealed enclosure. The enclosed volume was evacuated and partially filled with water to form a heat pipe. The heat pipe was centrally heated from its bottom and cooled along its top outer edge. Three liquid filling ratios and six heat fluxes from $2.5 \mathrm{~W} / \mathrm{cm}^{2}$ to $15 \mathrm{~W} / \mathrm{cm}^{2}$ were investigated. A decreasing lateral thermal resistance for an increasing applied heat flux was noted for all filling ratios until central dry-out. Central dry-out corresponds to the point where the evaporation rate outpaces the wicking of the working fluid at the centre of the heat pipe. Dry-out of the central wick results in a large thermal resistance compared to the pre-dry-out condition. Delayed dry-out onset was noted for increasing working fluid filling ratios. In the pre-dry-out condition, a peak average radial thermal conductivity of $920 \mathrm{~W} / \mathrm{m} \mathrm{K}$ was noted for a $65 \%$ filling ratio, and $7.5 \mathrm{~W} / \mathrm{cm}^{2}$ applied heat flux. A model was generated to calculate dry-out of the thermally sprayed porous wick for a given filling ratio and applied heat flux. The present research represents two highly novel advances in heat pipe technology. The first is the development of a new innovative manufacturing technique for the generation of a porous wick structure within a heat pipe. This new manufacturing technique enables the production of large metal vapour chambers with complex 3D geometries. When applied in conjunction with copper compatible working fluids, this techniques facilitates the realization of skin thermal conductors. Second, the fabrication of an ultra-large flat plate heat pipe that is significantly larger than that previously reported in the literature is demonstrated.
\end{abstract}

Keywords: Thermal spray, heat pipe, spray coating, vapour chamber, heat spreader

\section{Introduction}

The recent trend in creating information that is globally accessible has seen a paradigm shift in data processing and storage. Online utilities such as cloud computing and the Internet of Things, coupled with the demand for further miniaturization, local integration and stacking of photonics and electrical components has resulted in increasing generated power density and thermal fluxes [1-3]. These produced fluxes will soon exceed the capacity of traditional cooling methods [4,5]. Next-generation integrated circuits will require smart two-phase thermal solutions to achieve their cooling requirements.

Vapour chambers are widely used in many industrial applications in the chemical, power generation, HVAC, and aeronautical fields due to their high heat transfer coefficient [6]. They enable efficient transport of thermal energy by utilizing the latent heat associated with phase change [7,8]. A conventional vapour chamber consists of a sealed chamber that is partially filled with a liquid. The inner surface typically consists of a porous metal layer, known as a wick, that facilitates liquid recirculation. During operation, one section of the vapour chamber is placed in contact with a heat

${ }^{1}$ Co-first authorship, *Corresponding author 
source. At this location, the working fluid evaporates, carrying energy with it in the form of latent heat. This vapour diffuses through the heat pipe to the condenser, where it changes phase back into liquid form. This condensed liquid is then transported back to the evaporator through the wick by capillary forces.

Heat pipe performance is strongly dependent on the effectiveness of the wick to recirculate the working fluid from the condenser to the evaporator [9-11]. The critical heat flux (CHF) is the maximum heat flux a vapour chamber can dissipate before dry-out of liquid occurs at the evaporator. Wick dry-out happens when the feeding rate of the liquid through the wick is less than the evaporation rate of the working fluid. The performance of a wick structure is characterised by two critical parameters, permeability and capillarity [9-11]. Heat pipe wicks are traditionally constructed using woven wire meshes or sintered powders that are spot welded or sintered to the inner surfaces of the chamber [1215]. In a sintered wick, the pore size distribution depends on the powder size and the sintering process and can be difficult to control precisely. A sintered wick is also typically limited to simple flat or cylindrical geometries, while their size is limited by the size of the sintering chamber itself. Wire meshes are difficult to bond uniformly to the walls of a heat pipe, leading to localized areas of high thermal resistance and subsequent hot-spots.

Fathi et al. [10] studied the influence of thickness and particle size of sintered aluminum wicks on the CHF. Their results indicated that the CHF increases with increasing particle size and thickness. Weibel et al. [11] characterized the thermal resistance of several commonly used sintered copper powder wick structures with particle sizes from 45 to 355 $\mu \mathrm{m}$. They demonstrated that for a consistent wick thickness, the thermal resistances of the samples decreased as the particle size decreases from 355 to $120 \mu \mathrm{m}$. Any further reduction in their particle size reduced permeability, increasing thermal resistance. Attia et al. [16] investigated the effect of the filling ratio of the working fluids on the cooling performance of a vapour chamber. Their chamber was heated up by a highly concentrated heat source. They showed that the junction resistance or spreading resistance constituted roughly $60 \%$ of the overall thermal resistance of the vapour chamber [17].

Numerous studies have investigated alternative materials and fabrications techniques for potential future wick structures. Chen et al. [12] characterized and compared two low-cost aluminum vapour chambers with different wick structures: one with radial grooves and the other made from sintered aluminum powder. The optimal thermal resistances of the two vapour chambers were $24.2 \mathrm{~K} \cdot \mathrm{cm}^{2} / \mathrm{W}$ and $23.2 \mathrm{~K} \mathrm{~cm}^{2} / \mathrm{W}$, respectively when charged with acetone. They concluded that the enhanced thermal conductivity of the sintered powdered wick was due to its higher capillary forces. Wang et al. [17] designed a composite wick structure that is composed of copper foam core with radial and cross grooves in the evaporator of a vapour chamber to reduce the thermal spreading resistance. They observed that the spreading resistance decreased with the heating power until the onset of dry-out. Hwang et al. [18] constructed a low thermal resistance, multi-artery vapour chamber by using posts as liquid arteries and sintering a thin evaporator wick. The measured evaporator thermal resistance is less than $0.05 \mathrm{~K} \mathrm{~cm}^{2} / \mathrm{W}$ using a $1 \mathrm{~cm}^{2}$ heat source at a critical heat flux of $380 \mathrm{~W} / \mathrm{cm}^{2}$. The thermal resistance is dominated by the effective thermal conductivity of the evaporator wick and the conduction path through the receding meniscus within it [19]. All investigated vapour chambers were charged with water and centrally heated in a horizontal orientation. Wong et al. [20] developed a novel vapour chamber using a sintered porous wick on parallel grooves. They achieved a minimum thermal resistance of $0.16 \mathrm{~K} / \mathrm{W}$ at an applied heat flux of $124 \mathrm{~W} / \mathrm{cm}^{2}$, which was defined as the transition point, beyond which the thermal resistance increased sharply. Chen et al. [21] used a diamond-copper composition as the wick structure in their design. Their industrial diamond has a relatively high thermal conductivity of $2400 \mathrm{~W} / \mathrm{mK}$, which enhanced the thermal conductivity of their spreader when compared to a pure copper wick.

Ji et al. and Hansen et al. [13,22] explored the performance of highly porous copper and nickel foam wicks that were sintered to the inner surface of their vapour chambers. Ji et al. [13] showed that the high porosity and multiscale size of the copper foams 
enhanced the heat transfer rate and delayed the onset of CHF. A maximum heat flux of $216 \mathrm{~W} / \mathrm{cm}^{2}$ and a minimum thermal resistance of $0.09 \mathrm{~K} / \mathrm{W}$ were achieved. Gheitaghy et al. [23] used electrodeposition to create porous copper coatings on a copper substrate containing $0.5 \mathrm{~mm}$ deep channels created by electrodischarge machining. By controlling the evolution rate of hydrogen bubbles generated during electrodeposition, different porosities of the coating layers were created. Chen et al. [24] used an ion etching process to create $35 \mu \mathrm{m}$ high posts on their substrate and showed that the rate of capillary rise of methanol was dependent on the shapes of these posts. Though these techniques have given interesting results in a laboratory environment, they are generally time-consuming and expensive to implement, and none of them has been shown to be viable for commercial production [23,24].

The design of large flat plate heat pipes can be found in the literature [14,25-27]. The production of large scale heat pipes is primarily limited by their wick fabrication process. The size of the traditional sintered wick is restricted by the dimensions of the sintering chamber itself. Previous research in the field of ultra-large flat plate heat pipes is minimal. Liu et al.[27] produced a $300 \mathrm{~mm} \times 150 \mathrm{~mm} \times 5$ $\mathrm{mm}$ flat plate heat pipe utilizing a 200 count mesh as their wick. This approach is beneficial in producing a larger scale heat pipe than that achievable through the traditional sintering method. However, a mesh type wick typically generates a much lower capillary pressure and can suffer from poor thermal bonding, increasing the thermal resistance of the heat pipe. Both of these combine to limit this design approach to low power or lowgravity applications. Sigurdson et al.[25] produced a $300 \mathrm{~mm} \times 76 \mathrm{~mm} \times 4.5 \mathrm{~mm}$ thermal ground plate using a nanoporous titania wick fabricated by etching, laser welding and chemical oxidization. This heat pipe was 1.4 times smaller than the flat plate heat pipe presented in this work.

Traditionally heat pipe designs consist of two primary geometries: a flattened rod or a flat plate (vapour chamber). Both are found in most modern electronics, with the flat plate heat pipe applied to minimize local hotspots, while the flat rod heat pipe serves as a thermal highway between the flat plate heat pipe and the internal thermal dissipation solution (typically a fan). Large scale and irregular shaped heat pipes are an appealing technology for numerous fields such as LED lighting and car manufacturing. $70 \%$ of the energy used in LED lighting is emitted as thermal energy [28],. With the growing application of LED lighting and their increasing power densities, an intelligent thermal solution is required to reduce the need for large and bulky heat sinks. Incorporating large scale and irregular shaped heat pipes into LED lighting is a potential solution to this problem. Thermal spraying refers to a family of technologies in which powders or wires are fed into a high velocity and hightemperature gas jet so that molten metal droplets are propelled onto a target substrate where they coalesce and solidify to form a coating [29,30]. Thermal spraying can generate porous coatings by depositing a mixture of two materials and etching one of them out after coating [31,32]. Thermal spraying of wicks for heat pipes is an attractive proposition as it facilitates heat pipes fabrication on (a) large and (b) irregular shaped surfaces while achieving excellent thermal bonding characteristics. Thermal spraying is also a cost-effective, welldeveloped and straightforward process.

The novelty of this study is twofold; the first is the demonstration of a new manufacturing technique for the porous wicking structure in a heat pipe, and the second is the characterization of an ultra-large flat plate heat pipe that is significantly larger than that previously reported in the literature. The flat plate heat pipe was fabricated with a patterned, porous copper coating deposited on its interior surface using flame spraying. The porous coating acts as a wick through which water recirculates due to capillary forces. The morphology of the coating enhances evaporation heat transfer by increasing both the surface area wetted by the working fluid and the number of nucleation sites [9]. The wick fabrication process is cost-efficient, flexible and enables the coating of large areas with different, even curved, convex and concave, geometries, hence able to build a metallic "skin" with very high thermal conductivity. The thermal performance of the vapour chamber was characterized by heating it at the centre while cooling it along the edges and measuring the radial temperature distribution on the surface of the chamber. This temperature variation was used to define an equivalent thermal 

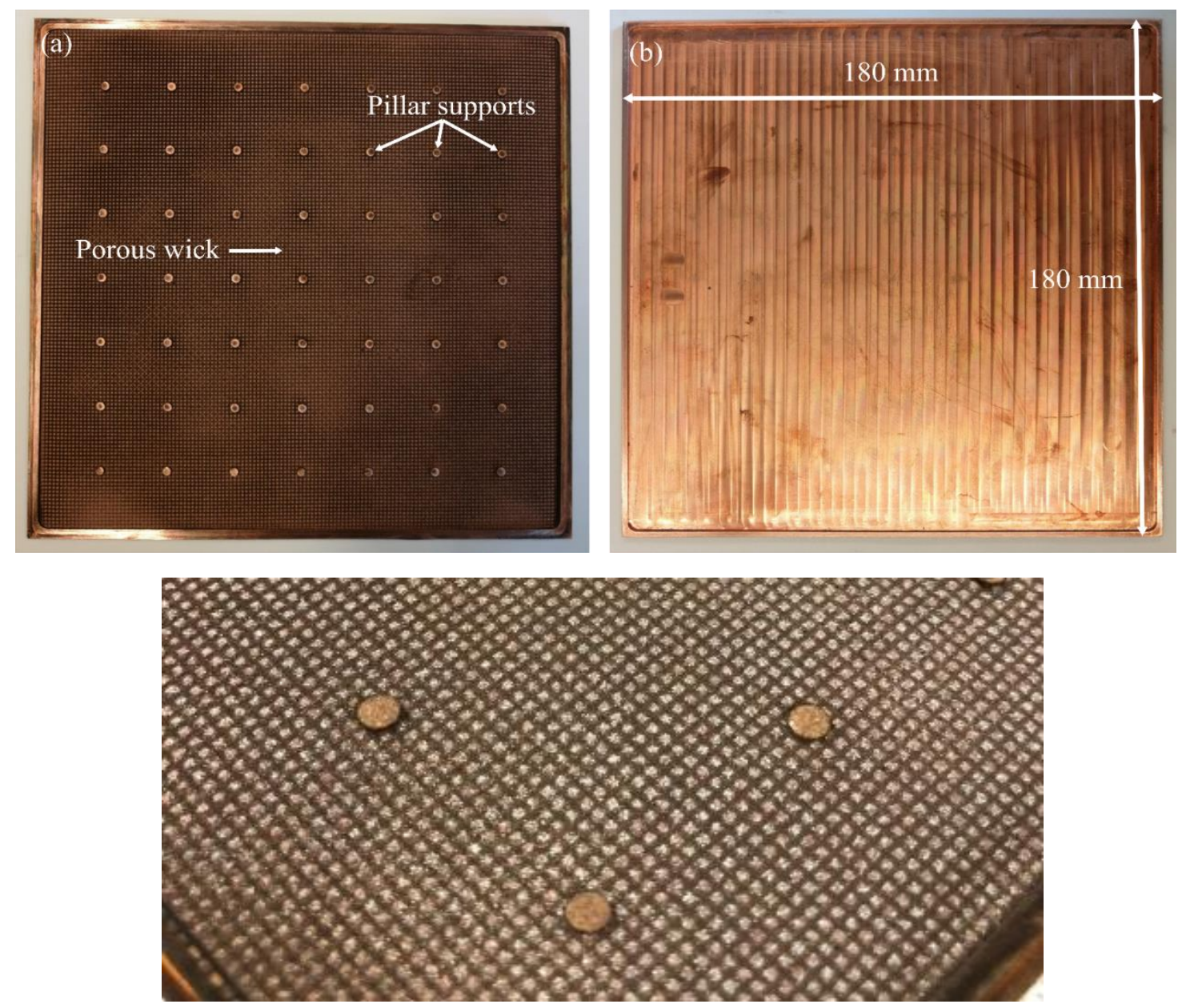

Fig. 1. (a) Heat pipe inner chamber bottom plate with thermal spray coating, (b) Heat pipe inner chamber top plate, without coating, (c) enlarged view of the porous coating.

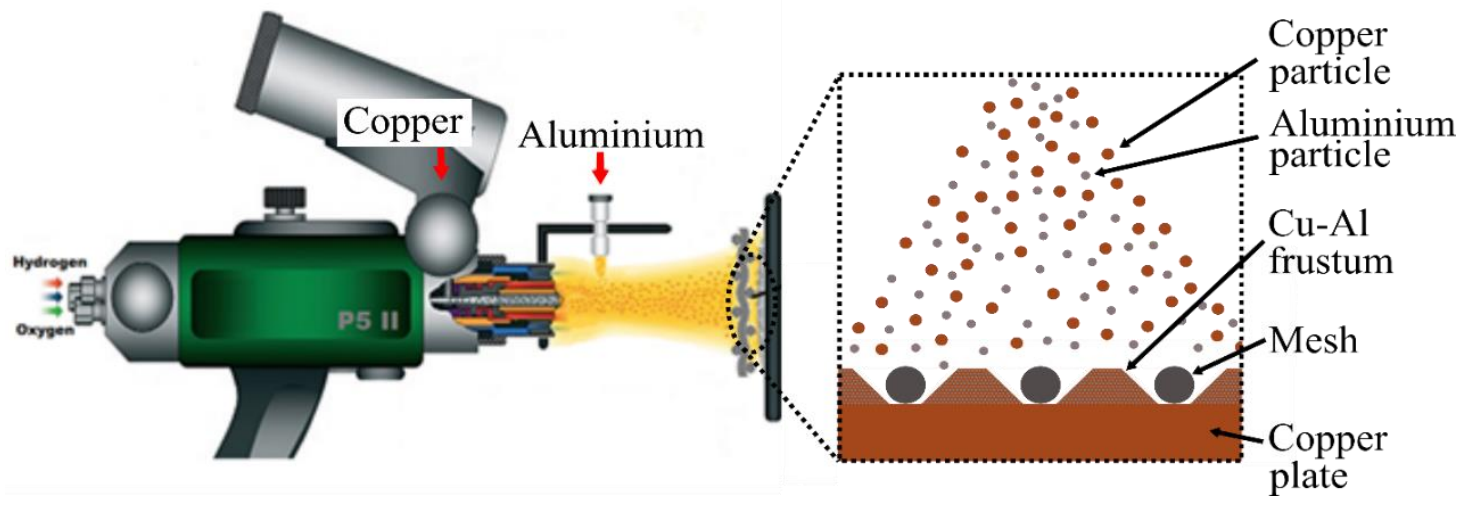

Fig. 2. Flame spray copper coating process.
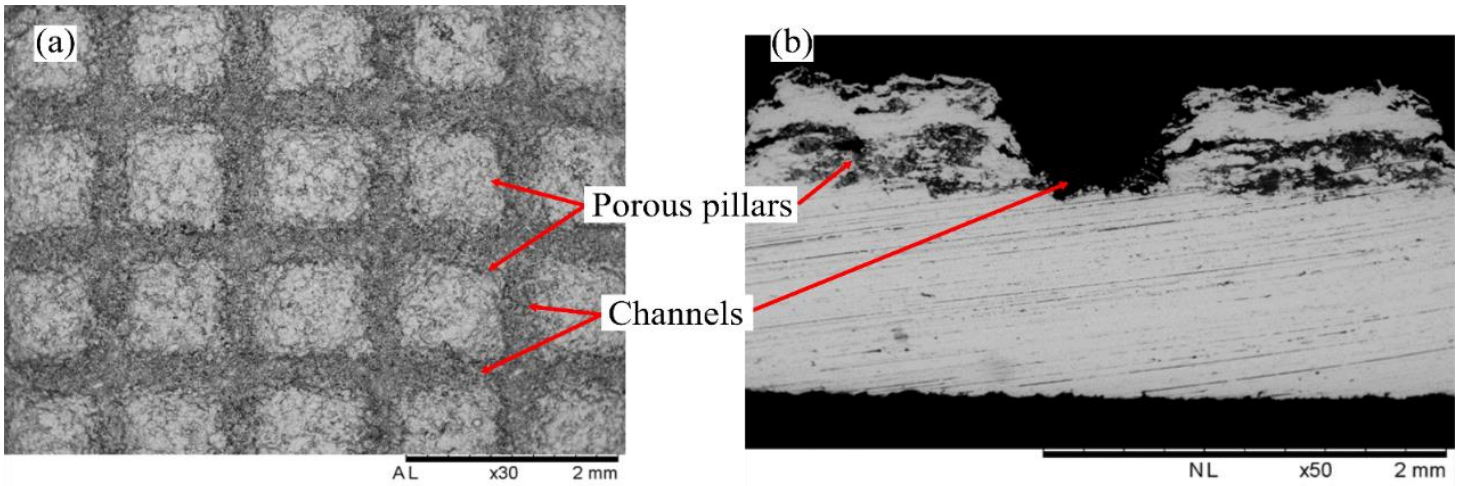

Fig. 3. Scanning Electron Microscope (SEM) image showing (a) top view of structured porous copper coating, and (b) SEM cross-section view of structured porous copper coating. 
conductivity, which was a measure of the heat spreading ability of the vapour chamber. The amount of water filled in the chamber and the applied heat flux were both varied.

\section{Experimental apparatus and data acquisition}

\subsection{Flat plate heat pipe}

The flat plate heat pipe (180 $\mathrm{mm} \times 180 \mathrm{~mm} \times 3 \mathrm{~mm})$ was constructed from two 110 copper plates (1012N57, McMaster-Carr, Elmhurst, Illinois, United States). Each plate was $2.4 \mathrm{~mm}$ thick initially; both plates were first skimmed down to $\sim 2$ $\mathrm{mm}$ to ensure planar surfaces, then a $1 \mathrm{~mm}$ recess was machined out of either plate to create a $176 \mathrm{~mm}$ $\times 176 \mathrm{~mm} \times 1 \mathrm{~mm}$ internal cavity once sealed together as shown in Figs. 1a and b. The top plate (Fig. 1b) was left uncoated, while the bottom (Fig. 1a) had 49 pillars, each $1 \mathrm{~mm}$ high and $3 \mathrm{~mm}$ in diameter to provide structural support and prevent the heat pipe from collapsing when its interior was evacuated. Fig. 1a shows the bottom plate after it was coated with a porous copper wick using flame spraying. A close-up view of the coating is shown in Fig. 1c.

In previous publications [31,32] the present authors have described the fabrication, wicking and evaporative characteristics of the structured porous coating in detail. The porous copper wick was fabricated using a flame spray torch (P5II, Flame Spray Technologies, Duiven, Netherlands) to deposit a mixture of copper $(99.9 \%, 53-88 \mu \mathrm{m}$, Alfa Aesar, Haverhill, Massachusetts, United States) and aluminum $(99.9 \%$, 35-63 $\mu \mathrm{m}$, Praxair Surface Technologies, QC, Canada) particles onto the target substrate. A stainless-steel wire mesh (9319T566, McMaster-Carr, Elmhurst, Illinois, United States) was placed on the substrate during coating, as shown in Fig. 2, to act as a mask. This methodology resulted in the formation of an array of pyramidshaped structures with channels between them (see Fig. 3a) after coating. These frustums are approximately $450( \pm 5) \mu \mathrm{m}$ in height and $890( \pm$ 10) $\mu \mathrm{m}$ square with $380( \pm 10) \mu \mathrm{m}$ wide channels between them. Their density is 62 frustums per centimetre squared.

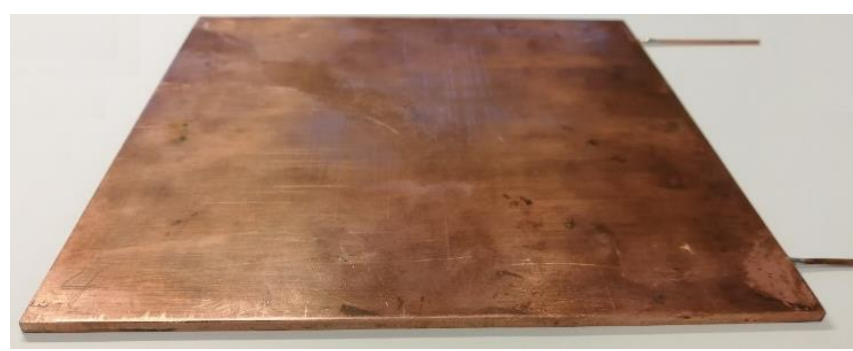

Fig. 4. Vacuum brazed vapour chamber fitted with one feeding line and one line for the pressure transducer.

After spraying, the aluminum is leached out by immersing the plate in a dilute $\mathrm{NaOH}$ solution. This produces a porous microstructure with a porosity of $44 \% \pm(5 \%)$. Fig. $3 \mathrm{~b}$ shows a cross-section through the plate after the coating has been sprayed on it, showing two of the porous structures and the channel between them. This structured coating, created by thermal spraying through the stainlesssteel mesh, enhances the permeability of the porous layer [31]. The structured wick combines both small pores in the frustums (large capillary pressure) and larger fluid paths between them for efficient liquid flow. The implemented channel dimensions and coating porosity in this research were selected based on previous research by the current authors $[31,32]$. These geometries optimize capillary pressure and the working fluid flow rate. An inherent advantage of this coating process is its potential to coat large surface areas and its ability to deposit porous structures on irregular and curved substrates while achieving excellent thermal bonding characteristics.

The top and bottom plates were brazed together in a vacuum furnace (VAH $1212 \mathrm{HV}$, VAC AERO International, Oakville, ON, Canada) using silver brazing paste (STL-1205-655, SRA, Walpole, MA, USA). The completed vapour chamber is shown in Fig. 4. The vapour chamber was fitted with two 1.6 $\mathrm{mm}(1 / 16$ ") outer diameter copper tubes that were also brazed in place. The first tube is a feeding line, while the other connects to a pressure transducer (PX61C1-050AV, Omega, Saint-Eustache, QC, Canada) to monitor the pressure inside the chamber during operation. A miniature flush diaphragm sensor is employed to minimizes the added vapour chamber dead volume due to this measurement $(<0.5 \%$ of total internal volume). The internal volume of the empty heat pipe is $18 \mathrm{~mL}$ and was determined by filling the heat pipe with $99 \%$ ethanol. The working fluid used in the vapour chamber is distilled water. The water was degassed 
by bubbling helium gas through it for three hours before filling [33]. Three filling ratios, defined as the volume of water filled to the total empty volume, are investigated: $35 \%, 50 \%$ and $65 \%$. It is estimated that the wicking structure would be saturated at a $40 \%$ filling ratio. The heat pipe is completely evacuated $(<55 \mathrm{~Pa})$ and emptied before each filling using a vacuum pump (04 110-2130-40, Edwards Vacuum, Mississauga, ON, Canada).

\subsection{Thermal characterization facility}

The purpose of this research is to characterize the performance of the thermally sprayed wick for heat pipe applications. Since the flat plate heat pipe is thin $(3 \mathrm{~mm})$ its thermal resistance in the direction normal to its face is expected to be very low $\left(\sim 10^{-5}\right.$ to $\left.10^{-6} \mathrm{~m}^{2} \mathrm{~K} / \mathrm{W}\right)^{2}$, which is much less than the achievable thermal contact resistance between the heat pipe and the heater and chiller plates. Thus, thermal conductivity measurements of the heat pipe in this direction would have significant uncertainties, and it is also not particularly interesting for the intended applications of this technology. The experiment was therefore designed to measure the lateral heat transfer across the heat pipe, as for standard heat spreaders and vapour chambers.

A schematic diagram of the thermal characterization facility is shown in Fig. 5 and an exploded threedimensional view in Fig. 6. The apparatus was designed to give a measurement of the effective thermal conductivity of the heat pipe in the radial direction. The device acted as a heat spreader, taking heat from a localized source at its centre and transmitting it to a heat sink along its edges.

The heat pipe is clamped between a copper heating plate and an aluminum chiller plate. The heat pipe is centrally heated by a copper cylinder $(41.3 \mathrm{~mm}$ diameter x $15 \mathrm{~mm}$ height) placed on the heater plate (see Fig. 6). A thermal interface material (Conductonaut, $k=73 \mathrm{~W} / \mathrm{m} \mathrm{K}$, Thermal Grizzly, Hamburg, Germany) is used at the interface of the heater cylinder and heat pipe to minimize the thermal contact resistance. Heat is supplied via six cartridge heaters (35025K241, McMaster-Carr, Elmhurst, IL, United States), each $9.5 \mathrm{~mm}$ in diameter and $101.6 \mathrm{~mm}$ long with a power of 500 $\mathrm{W}$, that are embedded in the heater plate that was $215.9 \mathrm{~mm} \times 215.9 \mathrm{~mm} \times 15.9 \mathrm{~mm}$ in size. The heaters are electrically connected to two DC power supplies (PS-1000-55, Epsco, Bloomingdale, IL, USA). The top surface of the heat pipe is cooled along its outer edge by four copper strips $(12.8 \mathrm{~mm}$ $\mathrm{x} 163.2 \mathrm{~mm} \times 3.17 \mathrm{~mm}$ ) placed in a square arrangement (see Fig. 6). These strips are connected to the heat pipe using a thermally conductive tape $(1 / 2-5-8810, k=0.6 \mathrm{~W} / \mathrm{m} \mathrm{K}, 3 \mathrm{M}$, Milton, ON, Canada). Thermal insulation (Cryogel z, $k=0.017$ $\mathrm{W} / \mathrm{m} \mathrm{K}$, Aerogel, Northborough, MA, USA) is placed above and below the heat pipe to ensure that all generated thermal energy flows laterally through the heat pipe.

Four T-type thermocouples are placed radially outward through the chiller plate into the thermal insulation on the top of the heat pipe to determine heat transfer in the upward direction through the insulation into the chiller block. Using Fourier's 1D conduction equation, and using spatially averaged temperature measurements for the heat pipe and chiller plate, a maximum heat flow loss of $7 \%$ in the upward direction through the insulation was calculated. This was precautionarily accounted for in all heat transfer calculations. The top surfaces of the copper strips are clamped to the aluminum chiller plate (see Fig. 5) that was $215.9 \mathrm{~mm} \times 215.9$ $\mathrm{mm} \times 15.9 \mathrm{~mm}$ in size with internal flow passages $12.7 \mathrm{~mm}$ in diameter machined in it. Distilled water is circulated through the aluminum block by a chiller unit (N0772025, PolyScience, Niles, Illinois, USA) to maintain a constant temperature during testing. The inlet and outlet water temperatures are recorded using T-type thermocouples (TJ36-CPSS032G-12, Omega, Saint-Eustache, QC, Canada) inserted in the flow pipes, and the water flow rate is recorded using a flow meter (FLR1013, Omega, Saint-Eustache, QC, Canada). These values are used to calculate the power transferred through the heat pipe during testing. The mounting pressure between the heat pipe and the cooling and heating plates was kept constant at $400 \mathrm{kPa}$ for all tests. This was achieved by tightening the clamping screws connecting the chiller and heater plates to the

\footnotetext{
${ }^{2}$ Roughly estimated assuming the thermal conductivity of pure copper.
} 


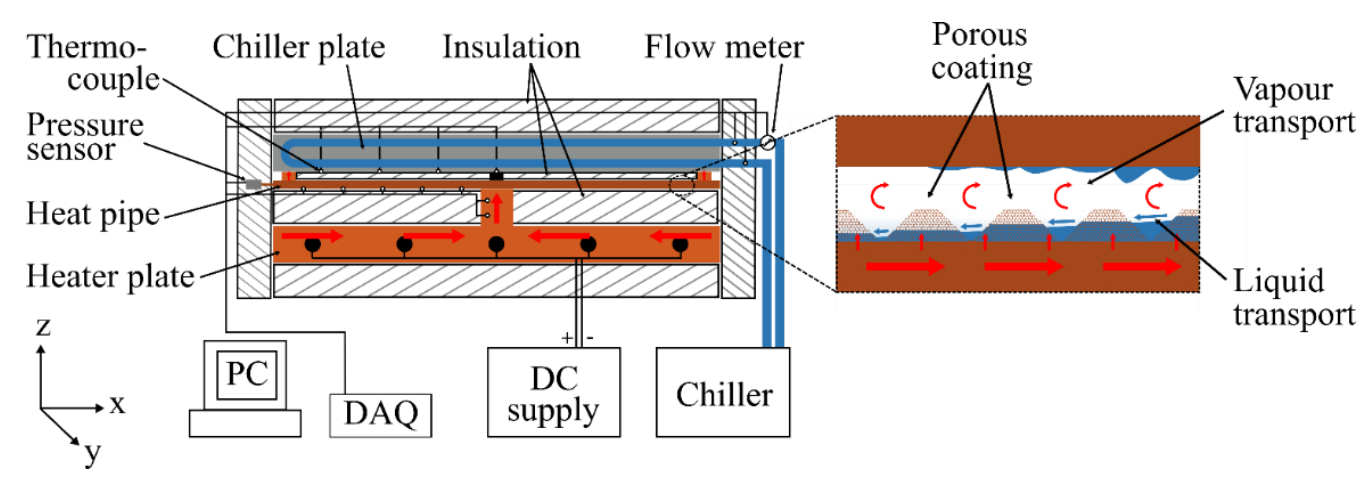

Fig. 5. Experimental schematic and operational description.

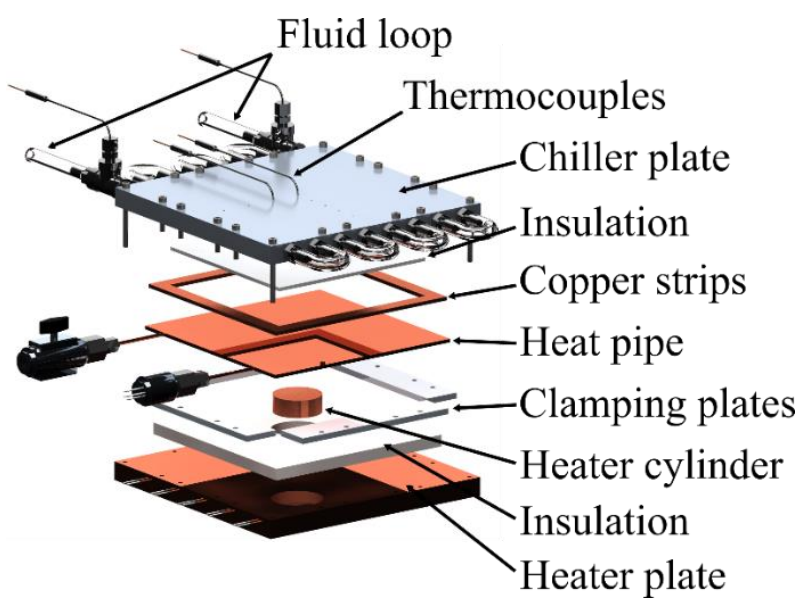

Fig. 6. Experimental facility exploded view.

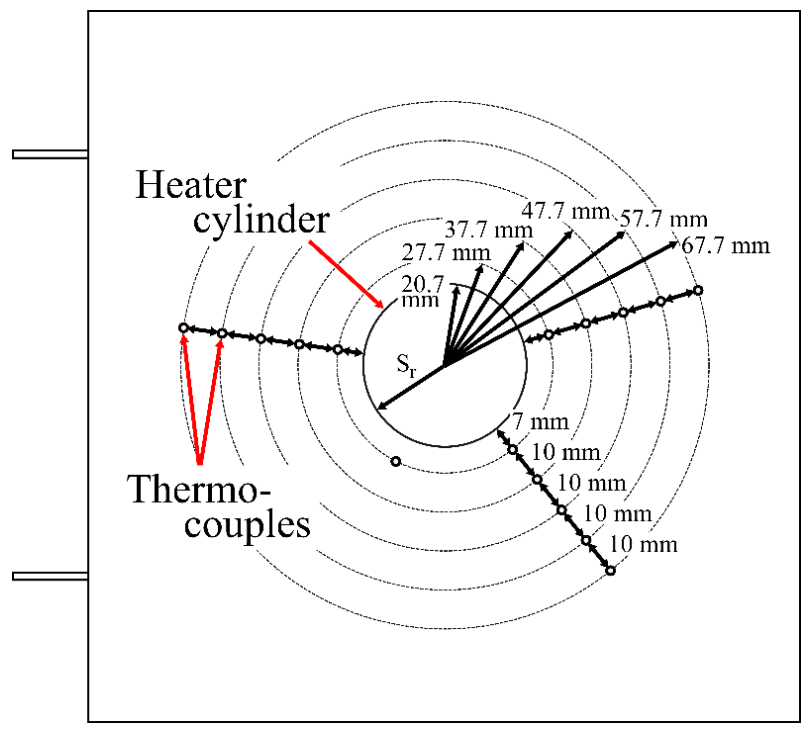

Fig. 7. Thermocouple placement diagram for the underside of the heat pipe.

desired pressure using a torque screwdriver (5716A21, McMaster-Carr, Elmhurst, Illinois, United States), ensuring a consistent thermal contact resistance throughout the system.

In order to determine the lateral thermal conductivity of the heat pipe, three sets of five $\mathrm{T}$ type thermocouples (GG-T-30-SLE, Omega, SaintEustache, QC, Canada) are fixed on the underside of the heat pipe, located on three lines radiating through concentric circles spaced $10 \mathrm{~mm}$ apart as shown in Fig. 7. $S_{r}$, shown in Fig. 7, is defined as the radial distance from the centre of the heat pipe. The three temperature readings on each concentric circle are averaged spatially and temporally to improve measurement accuracy and to check that heat flows radially outward in a uniform manner. An average calculated expanded uncertainty of $2.6 \%$ was noted for these readings across all tests. Heat transfer from the heater plate to the heat pipe through the insulation was calculated using a onedimensional heat conduction equation, where both surfaces are assumed isothermal. The heat flow through the insulation is found to be less than $1.5 \%$ of the heat input. A data acquisition system (OMBDAQ-56, Omega, Saint-Eustache, QC, Canada) is used to record all experimental measurements. Data is sampled at a frequency of $0.067 \mathrm{~Hz}$. All temperature, pressure and flow rate measurements are calibrated before testing. Finally, to minimize thermal losses to the surrounding environment, the entire thermal characterization facility is encapsulated in three layers of thermal insulation (Pyrogel XTE, $k=0.023 \mathrm{~W} \mathrm{~m} \mathrm{~m}^{-1} \mathrm{~K}^{-1}$, Aerogel, Northborough, MA, USA).

\section{Results and discussion}

A solid copper plate $(180 \mathrm{~mm} \times 180 \mathrm{~mm}$ and 3.17 $\mathrm{mm}$ thick) was analyzed in the thermal characterization apparatus to validate the performance of the facility and test method. The power generated by the cartridge heaters was varied from $2.5 \mathrm{~W} / \mathrm{cm}^{2}$ to $15 \mathrm{~W} / \mathrm{cm}^{2}$. The applied heat flux was calculated by dividing the generated power from the cartridge heaters with the cross-sectional area of the heater cylinder placed at the centre of the heater plate and heat pipe. Fig. 8 shows the measured temperatures as a function of radial 


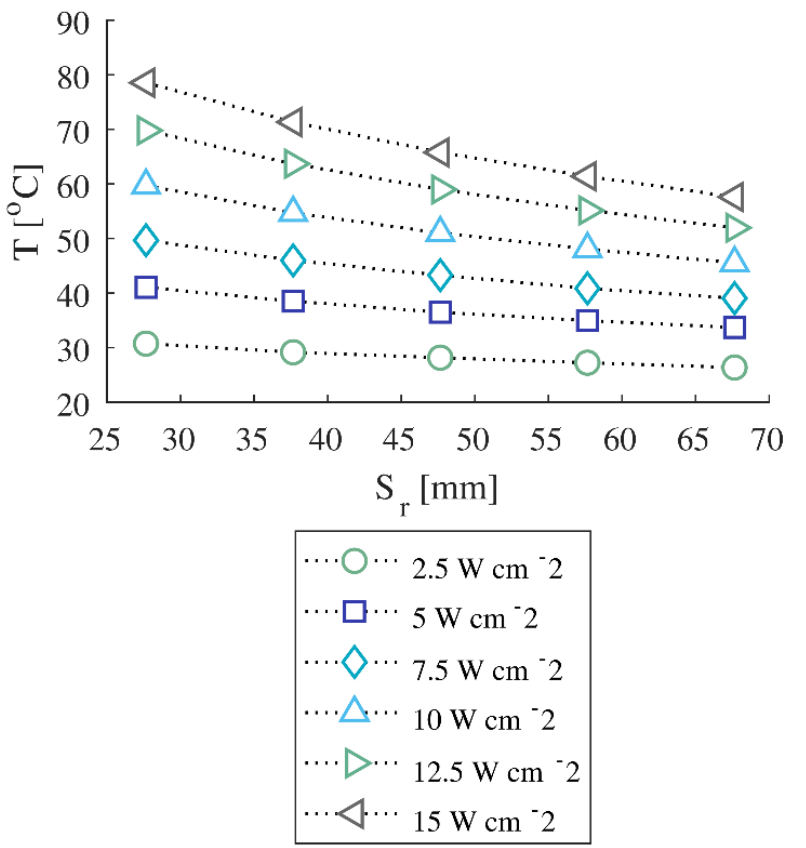

Fig. 8. Radial temperature variation in a solid copper plate heated at the centre and cooled along its edges.

position. The power through the heat pipe to the chiller plate is determined from the temperature rise of the water passing through the chiller plate [34]:

$$
q=\dot{m}_{c h} C_{p} \Delta T_{c h}
$$

where $\dot{m}$ is the mass flow rate of water through the chiller plate, $C_{p}$ is the specific heat capacity of the water and $\Delta T_{c h}$ is the difference in temperature between the inlet and outlet of the chiller plate. The difference in the power supplied by the cartridge heaters and that transported out of the chiller plate was due to losses through the insulation to the ambient air and were typically $<12.5 \%$.

The radial thermal conductivity $(k)$ of the copper plate is calculated from [34]:

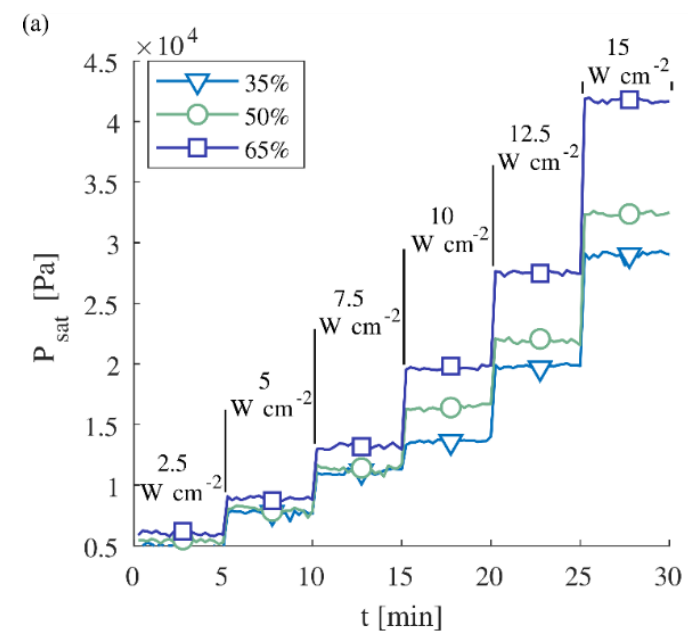

$$
k=\frac{q \ln \left(r_{2} / r_{1}\right)}{2 \pi L\left(T_{1}-T_{2}\right)}
$$

where $L$ is the thickness of the plate, $r_{1}$ and $r_{2}$ are the radial locations of the temperature measurements, and $T_{1}$ and $T_{2}$ are the temperatures at the radial locations, respectively. A near-constant thermal conductivity of $393.6 \mathrm{~W} / \mathrm{m} \mathrm{K}$ was calculated for all applied heat fluxes for the solid copper plate. The value of $k$ for copper reported in the literature is $390 \mathrm{~W} / \mathrm{m} \mathrm{K}$ [35], validating the applied test method.

The equivalent thermal conductivity of the vapour chamber was measured in experiments in which the applied heat flux was varied from $2.5 \mathrm{~W} / \mathrm{cm}^{2}$ to 15 $\mathrm{W} / \mathrm{cm}^{2}$ in $2.5 \mathrm{~W} / \mathrm{cm}^{2}$ increments. At each applied heat flux, the heat pipe is allowed to reach steadystate conditions; data is then acquired over 15 minutes resulting in 60 samples per test point.

Fig. 9a shows the variation in pressure $\left(P_{\text {sat }}\right)$ within the heat pipe measured by a miniature flush diaphragm pressure sensor as the applied heat flux was raised in $2.5 \mathrm{~W} / \mathrm{cm}^{2}$ increments, each step lasting for 5 minutes. Data is shown for the three liquid filling ratios tested. As the applied heat flux is increased $P_{\text {sat }}$ increases due to the higher temperature inside the chamber, which causes more water to evaporate. A higher filling ratio is observed to produce a larger pressure for a given applied heat flux for all cases. This suggests that partial dry-out has occurred in the vapour chamber so that the vapour is superheated. As the filling ratio is increased the empty volume (vapour space) in the chamber for the superheated vapour is reduced, resulting in increased pressure. Fig. 9b shows the saturation temperature corresponding to the (b)

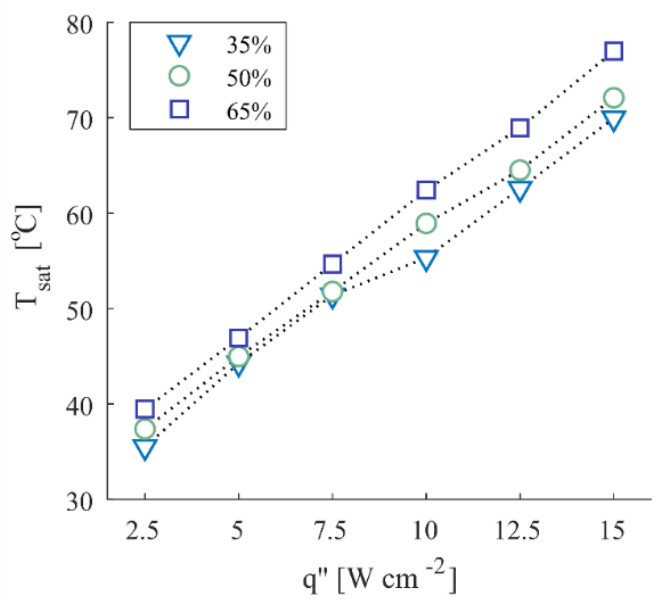

Fig. 9. (a) Saturation pressure and (b) temperature of the heat pipe for varied filling ratios and applied heat fluxes. 


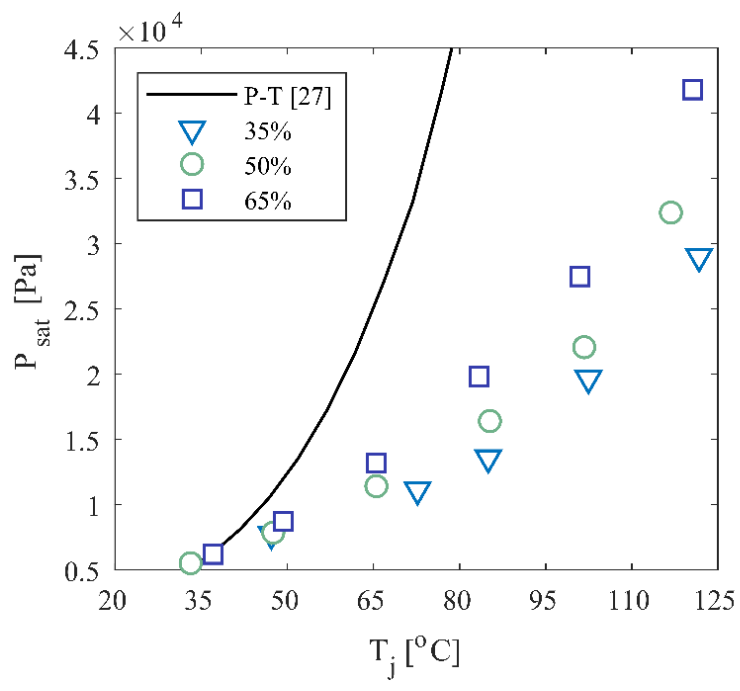

Fig. 10. Heater junction temperature vs saturation pressure for varied filling ratios and applied heat fluxes. The black line denotes the saturated pressure-temperature line for water [31].

measured pressure, calculated using linear interpolation from a saturated water properties table [34], as a function of applied heat flux. When no heat flux was applied, the measured vapour pressure equalled the tabled saturation pressure corresponding to the ambient air temperature, indicating that the concentration of noncondensable gases in the system was minimal. As long as the wick in the heat pipe remains wet, its temperature will remain below the saturation temperature shown in Fig. $9 \mathrm{~b}$ at a given heat flux.
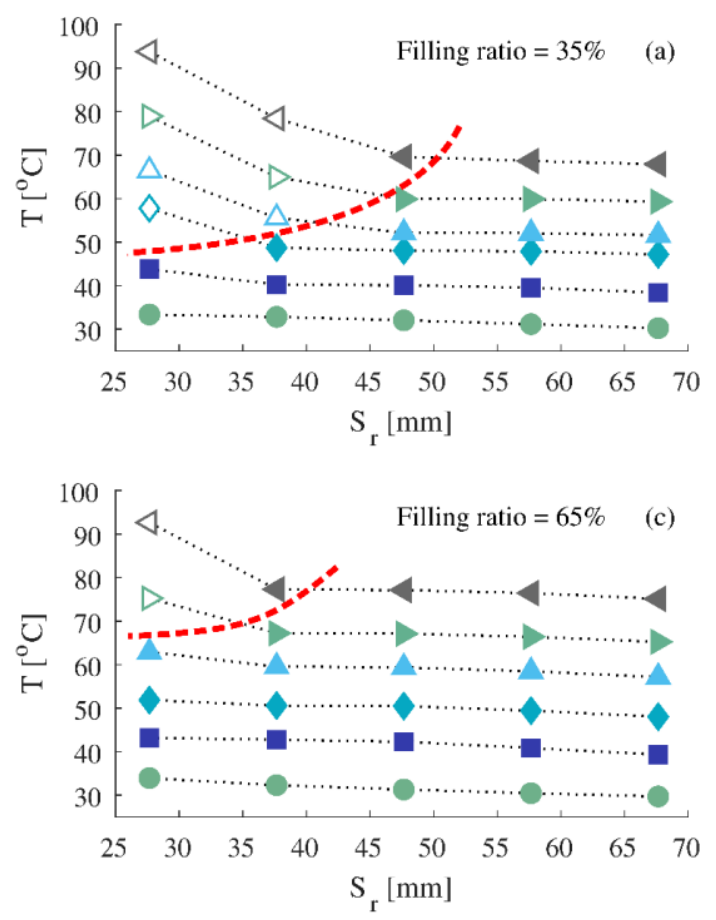

Fig. 10 compares the measured chamber pressure with the junction temperature $\left(T_{j}\right)$ of the heater block. The junction temperature is calculated by interpolating the temperature measurement along the length of the block in the direction of the heat flow. All filling ratios are shown and compared with the saturation pressure-temperature line for water [34]. At lower applied heat fluxes, the difference between theoretical saturation temperature and the junction temperature for all filling ratios is due to the thermal contact resistance across the interface of the heater block and vapour chamber. At higher applied heat fluxes, the central dry-out of the wick occurs, and a significant thermal resistance is established in the lateral direction of the vapour chamber resulting in an increasing difference between the theoretical saturation temperature and the junction temperature for a given saturation pressure. This is discussed further in Fig. 11.

Fig. 11 shows the temperatures measured on the surface of heat pipes being heated at their centres as a function of radial distance from the centre. Data is presented for three liquid filling ratios: 35\% (Fig. 11a), 50\% (Fig. 11b) and 60\% (Fig. 11c). Empty markers denote when the local temperature is greater than the calculated saturation temperature within the heat pipe chamber, implying that wick dry-out has occurred in this region. For all cases, at the lower applied heat fluxes $\left(2.5\right.$ and $\left.5 \mathrm{~W} \mathrm{~cm}^{-2}\right)$, no
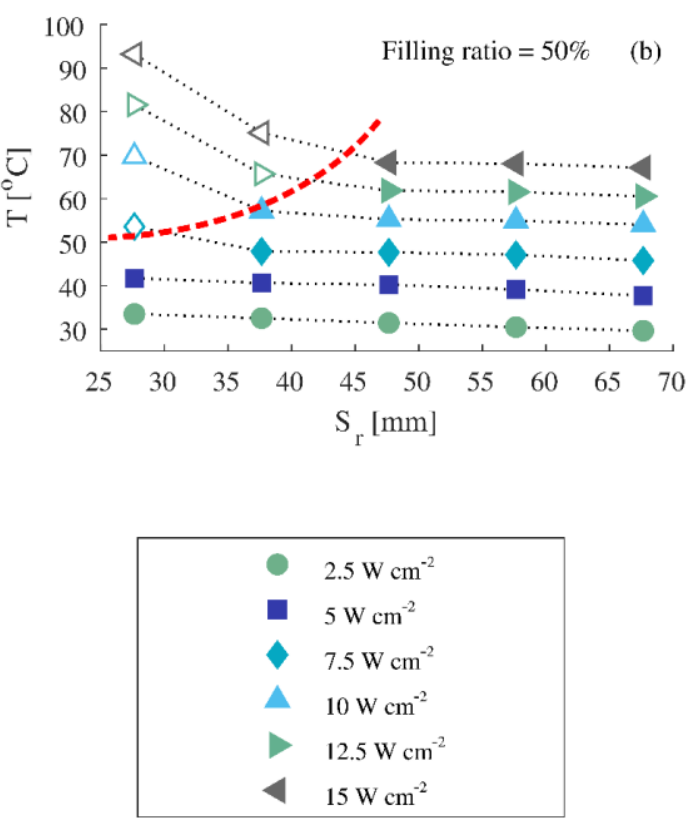

Fig. 11. Radial temperature distribution for different applied heat fluxes. (a) $35 \%$, (b) $50 \%$, and (c) $65 \%$. Filled markers denote non-dry out condition, empty markers represent when dry out has occurred. The red dashed line shows the dry out prediction from the dry out model. 
dry-out is observed; as the applied heat flux is increased, the onset of dry-out is noted for the $35 \%$ and $50 \%$ cases at a flux of $7.5 \mathrm{~W} / \mathrm{cm}^{2}$. Once dry-out occurs, further increase of the applied heat flux at the evaporator increases the dry-out region for all filling ratios. This is observed by a distinct increase in the temperature difference between adjacent thermocouples due to the increased lateral thermal resistance. Delayed onset of wick dry-out is observed as the filling ratio is increased, with dryout only occurring at the higher two applied fluxes $\left(12.5 \mathrm{~W} / \mathrm{cm}^{2}\right.$ and $\left.15 \mathrm{~W} / \mathrm{cm}^{2}\right)$ for the largest filling ratio of $65 \%$. The greater amount of liquid in the chamber serves to aid in the recirculation of fluid back to the evaporator, delaying the onset of dryout.

During operation, the working fluid is evaporated from the central region (evaporator) and circulates towards the outer edge of the heat pipe where it condenses (condenser). The condensed liquid is then recirculated back to the evaporator due to capillary forces in the porous wick. The heat pipe is insulated on all sides except at the evaporator and condenser. Thus, thermal energy is only transported in the radial direction, and its performance is determined by the ability of the thermally sprayed wick to recirculate sufficient working fluid to the evaporator. Once the rate of evaporation is higher than the rate of fluid recirculation dry-out will occur at the centre of the heat pipe. As the applied heat flux is increased further, the region of dry-out will grow radially outward as shown in Fig. 11. The red lines in Fig. 11 represents a theoretical prediction of heat pipe dry-out from a model that will be discussed below.

Lips et al. [36] developed a model to examine the effect of filling ratio on the performance of a flatplate heat pipe. Fig. 12. shows the fluid distribution within the chamber of the flat plate heat pipe during operation. The liquid layer is thickest at the condenser (outer radial edge) and thinnest near the evaporator (centre). As the amount of water in the heat pipe changes, the distribution of liquid within the vapour chamber changes [36]. Fig. 13 shows three different possible liquid distributions within the heat pipe for varied liquid filling ratios. For lower filling ratios, the water either partially (Fig. 13a) or completely (Fig. 13b) fills the porous wick. As the filling ratio is increased, it is possible for the liquid to extend to the top plate. This occurs when the vapour space thickness $\left(H_{v}\right)$ is less than a critical value $\left(H_{c}\right)$. Wetting of the top surface takes place

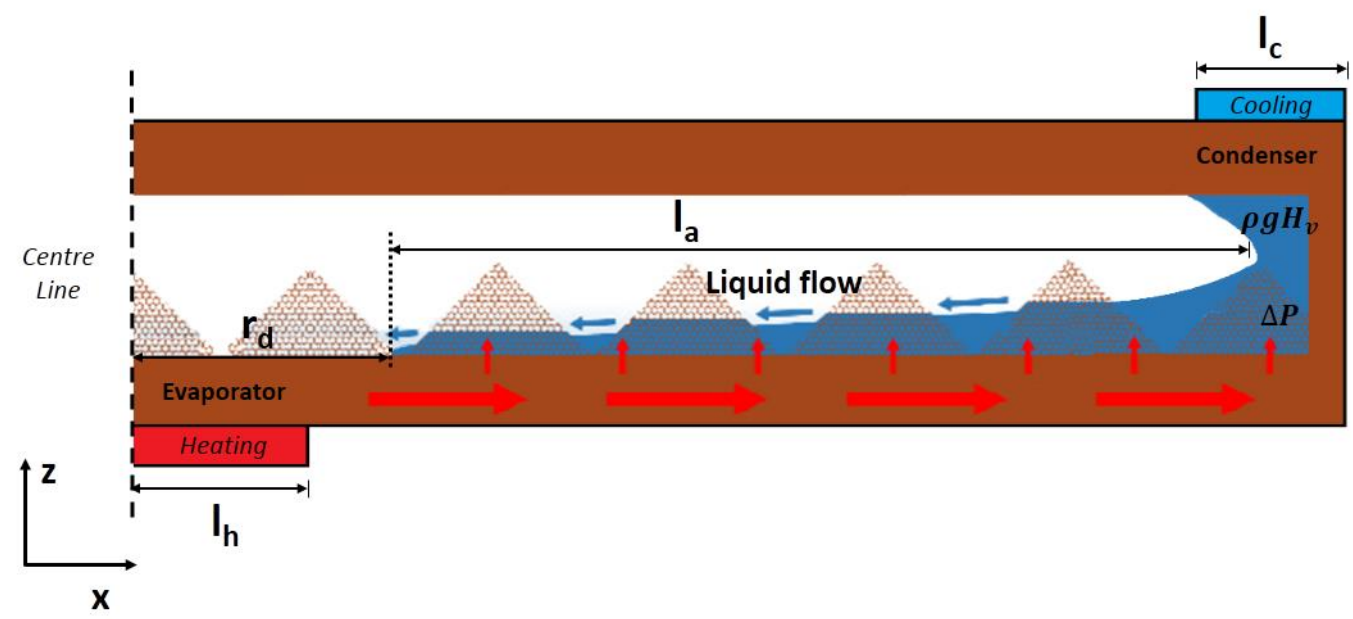

Fig. 12. Fluid distribution within the heat pipe chamber during operation for a centrally heated and edge cooling case.

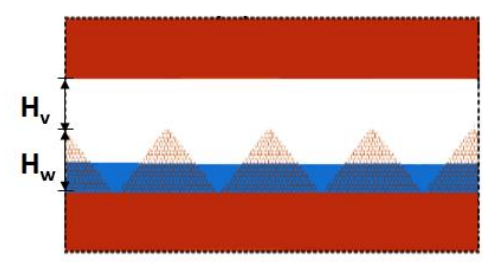

(a)

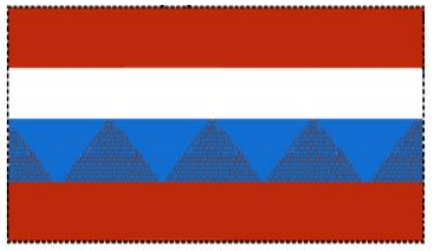

(b)

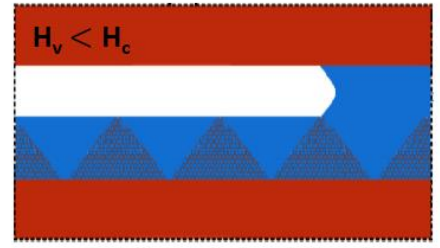

(c)

Fig. 13. Liquid distribution in a horizontal flat plate heat pipe. 
near the condenser as the fluid is thickest here during operation. In this case, the water will extend to the top plate and be dragged to the sidewall of the chamber due to capillary forces (Fig. 13c). As the filling ratio is increased further, the water layer will extend radially inward until the chamber is fully charged with water. The critical thickness of the vapour layer above the meniscus $\left(H_{c}\right)$ is calculated by [36]:

$$
H_{c}=\sqrt{\frac{2 \sigma}{\left(\rho_{l}-\rho_{v}\right) g}\left(\cos \alpha_{w}+\cos \alpha_{s}\right)}
$$

Where $\sigma$ is the surface tension of water, $\rho_{l}, \rho_{v}$ the density of water in liquid and vapour forms, $g$ the gravitational acceleration, and $\alpha_{w}, \alpha_{s}$ are the water contact angles between the wick and the top plate, respectively. For the present study, $\alpha_{w}$ is close to zero as the wick is hydrophilic with an apparent contact angle of $0^{\circ}$, while $\alpha_{s}$ is $68^{\circ}$ for water on a smooth copper surface [37]. The calculated critical space of water meniscus is $4.56 \mathrm{~mm}$, which is much greater than the vapour space of the chamber 0.55 $\mathrm{mm}$. Therefore, if the chamber is charged with sufficient water to fill the wick (filling ratio $>40 \%$ ), the water will wet the top surface of the internal chamber.

The CHF of a heat pipe is determined by the ability to recirculate condensed working fluid back from the condenser to the evaporator through the porous wick. Once the rate of evaporation is greater than the rate of fluid recirculation dry-out will occur at the centre of the heat pipe. As the applied heat flux is increased further, the region of dry-out will grow radially outward. The vapour chamber dry-out heat flux $\left(q_{d}^{\prime \prime}\right)$ is calculated using:

$$
q=q_{d}^{\prime \prime} A_{e}=\dot{m} h_{f g}
$$

where $q_{d}^{\prime \prime}$ the dry-out flux, $A_{e}$ is the heating cylinder top surface area, $\dot{m}$ the liquid flow/feed rate in the wick, and $h_{f g}$ is the latent heat of vaporization. Liquid flow in porous wick structure is governed by Darcy's Law [38], which states that the volume flow rate of liquid $(\dot{Q})$ through the pores is given by:

$$
\dot{Q}=\frac{k_{p}}{\mu} A_{f} \frac{d P}{d x}
$$

where $A_{f}$ is the cross-sectional area available for flow. For a water-saturated wick $A_{f}=\varepsilon_{\mathrm{e}} A_{c}$, where $\varepsilon_{e}$ its effective porosity and $A_{c}$ is the nominal crosssection of the wick at the dry-out radius $r_{d} . A_{c}$ is calculated from $A_{c}=2 \pi r_{d} H_{w}$, where $H_{w}$ is the wick thickness, $k_{p}$ is the permeability of the wick, and $\mu$ is the dynamic viscosity of water. Then, the liquid flow/feed rate $\left(\dot{m}_{w}\right)$ in the wick is given by:

$$
\dot{m}_{w}=\rho \dot{Q}=\frac{\rho}{\mu} k_{p} \varepsilon_{e} A_{c} \frac{d P}{d x}
$$

Substituting Eq. 6 into Eq. 4 and using the definition of the kinematic viscosity $v=\frac{\mu}{\rho}$ we find:

$$
q_{d}^{\prime \prime}=h_{f g} \frac{k_{p} \varepsilon_{e} A_{c}}{v A_{e}} \frac{d P}{d x}
$$

The pressure gradient in a porous wick has two components: a capillary pressure due to surface tension forces in pores and a hydrostatic head due to the layer of liquid above the wick. For a larger filling ratio, the water meniscus occupies the vapour space and the thickness is $H_{v}$. For a horizontal heat pipe it assumes that the liquid pressure varies linearly with distance in the wick. When the liquid flows under the capillary pressure $\left(\Delta P_{\text {cap }}\right)$ from the condenser to its dry-out radius, a gravity pressure head is added to the system and enhances the water flow in the wick, as shown in Fig. 12. For filling ratio greater than $40 \%$ (wick is saturated with working fluid), the pressure gradient driving flow is:

$$
\frac{d P}{d x}=\frac{\Delta P_{c a p}+\rho g H_{v}}{l_{\text {eff }}}
$$

where $l_{e f f}$ is the effective thermal length of the vapour chamber [37]. In this case, the effective thermal length is defined as:

$$
l_{\text {eff }}=\frac{l_{\text {heat }}+l_{\text {cool }}}{2}+l_{m}
$$

Where $l_{\text {heat }}$ and $l_{\text {cool }}$ are the lengths of the heating and cooling area, respectively (see Fig. 12). The distance travelled by the water from the liquid meniscus to the dry-out radius is $l_{m}=l_{t}-r_{d}$ where $l_{t}$ is the distance from the centre of the chamber to the liquid meniscus, which can be calculated from the volume of water and the vapour space. In this case, when the filling ratio is larger than that required to saturate the wick, it will take up the vapour space of the chamber and shorten the travelling distance of water in the wick from the 


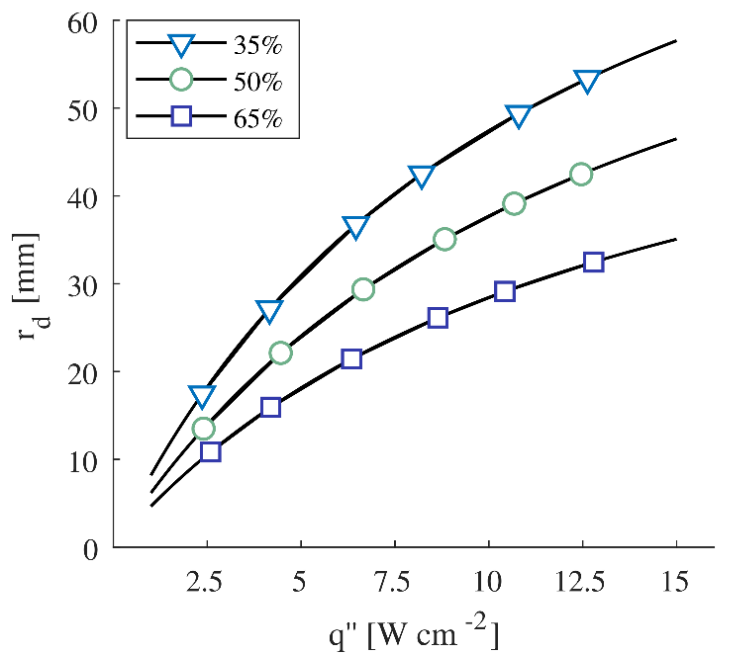

Fig. 14. Dry-out model for varied heat flux and filling ratio. Markers denote predicted dry-out radii for experimental data.

cold plate to the centre of the hot plate. Thus, the greater filling ratio enhances the pressure gradient of liquid within the wick and subsequently increases the maximum wicking rate.

Combining Eqs. 7 and 8 we obtain:

$$
q_{d}^{\prime \prime}=h_{f g} \frac{k_{p} \varepsilon_{e} A_{c}}{v A_{e}} \cdot\left(\frac{\Delta P_{c a p}+\rho g H_{v}}{l_{e f f}}\right)
$$

For saturated and oversaturated conditions, the dry-out radius $r_{d}$ can be solved as a function of the dry-out flux $\left(q_{d}^{\prime \prime}\right)$ by substituting Eq. 9 into 10, respectively, and rearranging,

$$
r_{d}=\frac{q_{d}^{\prime \prime} v A_{e}\left(\frac{l_{h e a t}+l_{c o o l}}{2}+l_{t}\right)}{2 h_{f g} \varepsilon_{e} \pi H_{w} k_{p}\left(\Delta P_{c a p}+\rho g H_{v}\right)+q_{d}^{\prime \prime} v A_{e}}
$$

where $\Delta P_{c a p}$ and $k_{p}$ are capillary pressure and permeability of the wick and are $1013 \mathrm{~Pa}$ and 3.37 $\times 10^{-11} \mathrm{~m}^{2}$ respectively. Those values were determined from a rate-of-rise test conducted in our previous study [31].

Fig. 14 plots the calculated dry-out radius for a given heat flux for various filling ratios. The markers show the predicted dry-out from the experimental data, where the heat flux, in this case, corresponds to that through the heat pipe and is found based on the generated power from Eq. 1. As the applied flux is increased, the dry radius increases. A minimum filling ratio of $40 \%$ is required to fill the porous wick. In tests with a $35 \%$ filling ratio, the wick would not have been fully saturated even before heating, and therefore increasing the filling ratio from $35 \%$ to $50 \%$

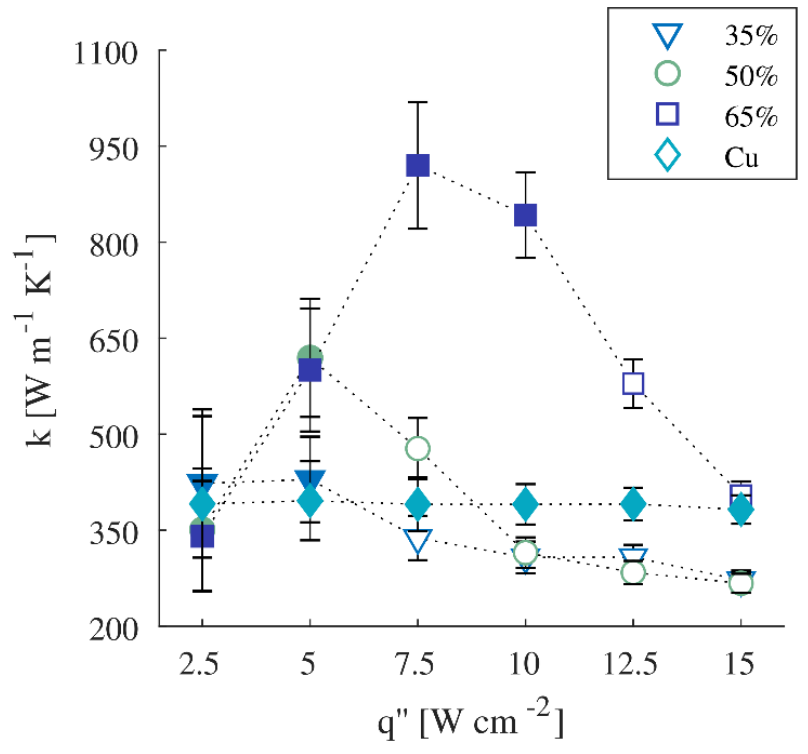

Fig. 15. Average radial thermal conductivity for varied applied heat flux and filling ratio. Filled markers denote non-dry-out condition. Empty markers represent when dry-out has occurred.

produces a larger change in dry-out radius than increasing it from $50 \%$ to $65 \%$. A comparison of the model results and experimental data are shown in Fig. 11, where the red dashed line on each plot shows the approximate calculated dry-out radii from the developed dry-out model for the given filling ratio and applied heat flux. It is calculated using Eq. 11 and it is included in Fig. 11 is used to contrast the theoretical prediction and the experimental results. Predictions from the model agree well with the observed dry-out radii.

Fig. 15 compares the applied heat flux with the average radial thermal conductivity for different heat pipe filling ratios. The thermal conductivity of a characterized solid copper plate of similar dimensions is also shown for comparison and is independent of the applied heat flux. The average thermal conductivity is calculated from Eq 2, using the temperatures on the innermost and outermost thermocouples, respectively. This approach minimizes the experimental uncertainty as it maximizes the temperature difference used for calculation. The experimental uncertainty for all parameters was examined using the methodology outlined by Kirkup and Frenkel [39]. All listed values are to a $95 \%$ confidence level. First, the standard uncertainty of the acquired test data is determined. A combined uncertainty approach is then applied to Eqs. 1 and 2. The expanded uncertainty for the lateral thermal conductivity is shown graphically in Fig. 15. The empty markers denote when the onset of dry-out within the heat 


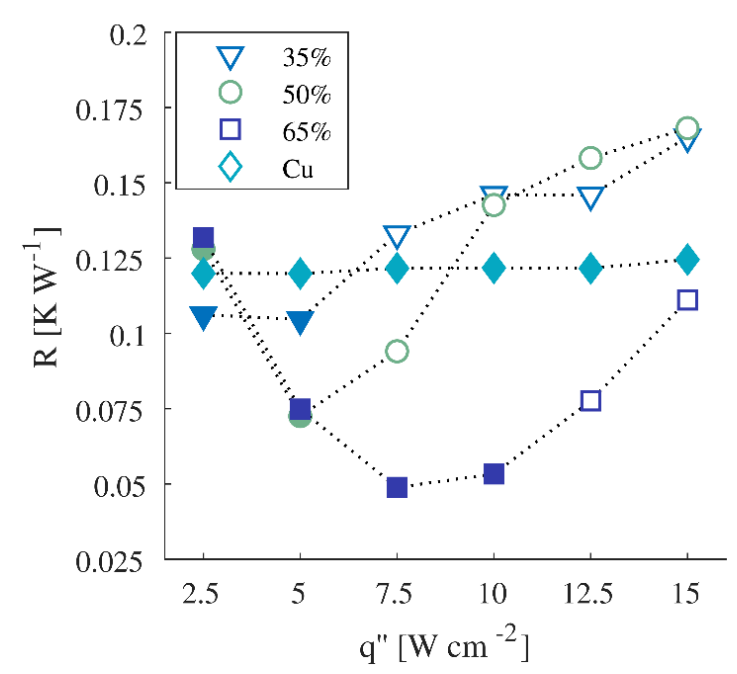

Fig. 16. Average radial thermal resistance for varied applied heat flux and filling ratio. Filled markers denote non-dry-out condition. Empty markers represent when dry-out has occurred.

pipe has occurred. For the flat plate heat pipe, a sharp decrease in lateral thermal conductivity is observed with the onset of dry-out. Once dry-out occurs, the primary heat transfer mechanism is heat conduction through the walls and porous wick of the heat pipe rather than the transport of latent heat along with diffusing vapour. As noted in Fig. 11, larger filling ratios delay the onset of dry-out. The largest radial thermal conductivity of $920 \mathrm{~W} \mathrm{~m}^{-1} \mathrm{~K}^{-}$ 1 is observed for the greatest filling ratio and an applied heat flux of $7.5 \mathrm{~W} \mathrm{~cm}^{-2}$. This indicates a performance increase of 2.4 times over pure copper alone while the weight of the chamber was $33 \%$ less than that of the copper plate. At the lowest applied heat flux of $2.5 \mathrm{~W} \mathrm{~cm}^{-2}$, the lowest filling ratio demonstrates the largest radial thermal conductivity of $430 \mathrm{~W} \mathrm{~m}^{-1} \mathrm{~K}^{-1}$.

Fig. 16 shows the radial thermal resistance of the heat pipe for different applied heat fluxes and filling ratios. The lateral thermal resistance is defined as [34]:

$$
R=\left(T_{\max }-T_{\min }\right) / q
$$

where $T_{\max }$ and $T_{\min }$ are the highest and lowest measured temperatures, respectively. The measured thermal resistance of the solid copper plate is also plotted as a form of comparison. A minimal thermal resistance of $0.05 \mathrm{~K} / \mathrm{W}$ is observed for the greatest filling ratio for an applied heat flux of $7.5 \mathrm{~W} / \mathrm{cm}^{2}$. This value is significantly lower than the optimum value of $0.2 \mathrm{~K} / \mathrm{W}$ noted by Lips et al. [36] for their work.

\section{Conclusions}

A new innovative manufacturing technique for the generation of a porous wick within a heat pipe has been demonstrated. With this technique, an ultralarge flat plate heat pipe that is significantly larger than that previously reported in the literature has been fabricated and thermally characterized. The porous copper wick was constructed by flame spraying a copper-aluminum mixture onto a copper plate through a stainless-steel mesh and then removing the aluminum. The effects of varying the applied heat flux and liquid filling ratio were studied. The copper vapour chamber was tested with three filling ratios of water and up to $200 \mathrm{~W}$. The radial thermal conductivity increased with applied heat flux, prior to the onset of dry-out, for all filling ratios. A peak radial thermal conductivity of 920 $\mathrm{W} / \mathrm{m} \mathrm{K}$ is observed for the largest filling ratio of $65 \%$ for an applied heat flux of $7.5 \mathrm{~W} / \mathrm{cm}^{2}$. This represents a 2.4 times performance increase and a $33 \%$ reduction in weight over pure copper. The lowest filling ratio of $35 \%$ was shown to performed better at the lowest applied heat fluxes than its $50 \%$ and $65 \%$ counterparts. A model was developed to calculate the evaporator dry-out radius for a given applied heat flux and filling ratio. Predictions from the model agreed well with the experimental data. Dry-out was noted when the rate of fluid recirculation to the central region of the heat pipe was less than the rate of evaporation, which produced a sharp increase in the lateral thermal resistance. Once dry-out occurs further increase of the applied heat flux results in the dry-out region growing radially outward. This work highlights the performance and viability of a thermally sprayed porous wick for heat pipe application. This technology is an attractive technique to deposit porous coatings on large, irregular surfaces and overcoming limitations associated with traditional wick fabrication techniques. 


\begin{tabular}{|c|c|c|c|}
\hline \multicolumn{4}{|c|}{ Nomenclature } \\
\hline$A$ & area $\left[m^{2}\right]$ & $f$ & flow \\
\hline$C p$ & specific heat capacity $\left[J \mathrm{~kg}^{-1} \mathrm{~K}^{-1}\right]$ & heat & heating \\
\hline$g$ & gravitational acceleration $\left[\mathrm{m} \mathrm{s}^{-2}\right]$ & $j$ & junction \\
\hline$H_{c}$ & thickness $[m]$ & $l$ & liquid \\
\hline$H_{f g}$ & latent heat of vapourization $\left[\mathrm{kJ} \mathrm{kg}^{-1}\right]$ & $m$ & meniscus \\
\hline$k$ & thermal conductivity $\left[W \mathrm{~m}^{-1} K^{-1}\right]$ & $\max$ & maximum \\
\hline$k_{p}$ & wick permeability [-] & $\min$ & minimum \\
\hline$L$ & plate thickness $[\mathrm{m}]$ & $r$ & radial \\
\hline$l$ & length $[m]$ & $s$ & solid \\
\hline$\dot{m}$ & mass flow rate $\left[\mathrm{kg} \mathrm{s}^{-1}\right]$ & sat & saturation \\
\hline$P$ & pressure $\left[\mathrm{N} \mathrm{m}^{-2}\right]$ & $t$ & centre chamber to liquid meniscus \\
\hline$q$ & heat transfer rate $[\mathrm{W}]$ & $v$ & vapour \\
\hline$q^{\prime \prime}$ & heat flux $\left[W m^{-2}\right]$ & $w$ & wick \\
\hline$R$ & thermal resistance $\left[K W^{-1}\right]$ & & \\
\hline$r$ & radial coordinate $[m]$ & \multicolumn{2}{|c|}{ Greek Symbol } \\
\hline$S$ & coordinate $[\mathrm{mm}]$ & $\alpha$ & water contact angle $\left[^{\circ}\right]$ \\
\hline$T$ & temperature $[\mathrm{K}]$ & $\Delta$ & differential [-] \\
\hline & & $\varepsilon$ & porosity [\%] \\
\hline \multicolumn{2}{|c|}{ Subscript } & $\mu$ & dynamic viscosity $\left[\mathrm{Ns} \mathrm{m}^{-2}\right]$ \\
\hline$c$ & critical & $v$ & kinematic viscosity $\left[\mathrm{m}^{2} \mathrm{~s}^{-1}\right]$ \\
\hline cap & capillary & $\rho$ & density $\left[\mathrm{kg} \mathrm{m}^{-3}\right]$ \\
\hline$c h$ & chiller & $\sigma$ & surface tension $\left[\mathrm{N} \mathrm{m}^{-1}\right]$ \\
\hline cool & cooling & & \\
\hline$d$ & dry-out & \multicolumn{2}{|c|}{ Acronyms } \\
\hline$e$ & evapourator & $\mathrm{CHF}$ & critical heat flux \\
\hline eff & effective & & \\
\hline
\end{tabular}

\section{References}

[1] N.Z. Haron, S. Hamdioui, Why is CMOS scaling coming to an END?, in: Proc. - 2008 3rd Int. Des. Test Work. IDT 2008, 2008. https://doi.org/10.1109/IDT.2008.4802475.

[2] A. Bar-Cohen, J.J. Maurer, J.G. Felbinger, Darpa's intra/interchip enhanced cooling (icecool) program, in: 2013 Int. Conf. Compd. Semicond. Manuf. Technol. CS MANTECH 2013, 2013.

[3] S.S. Iyer, The evolution of dense embedded memory in high performance logic technologies, in: Tech. Dig. - Int. Electron Devices Meet. IEDM, 2012. https://doi.org/10.1109/IEDM.2012.6479155.

[4] N. Kumari, R. Shih, S. Escobar-Vargas, T. Cader, A. Govyadinov, S. Anthony, C. Bash, Air cooling limits of 3D stacked logic processor and memory dies, in: Thermomechanical Phenom. Electron. Syst. Proceedings Intersoc. Conf., 2014. https://doi.org/10.1109/ITHERM.2014.68922 69.

[5] T.J. Chainer, M.D. Schultz, P.R. Parida, M.A. Gaynes, Improving data center energy efficiency with advanced thermal 
management, IEEE Trans. Components, Packag. Manuf. Technol. 7 (2017) 12281239.

[6] S.T. Tu, H. Zhang, W.W. Zhou, Corrosion failures of high temperature heat pipes, Eng. Fail. Anal.

(1999).

https://doi.org/10.1016/S1350-

6307(98)00057-0.

[7] J.H. Rosenfeld, Porous media heat exchangers for cooling of high-power optical components, Opt. Eng. (1995). https://doi.org/10.1117/12.194100.

[8] M. Mochizuki, T. Nguyen, K. Mashiko, Y. Saito, T. Nguyen, V. Wuttijumnong, A Review of Heat Pipe Application Including New Opportunities, Front. Heat Pipes. (2011). https://doi.org/10.5098/fhp.v2.1.3001.

[9] D. Deng, D. Liang, Y. Tang, J. Peng, X. Han, M. Pan, Evaluation of capillary performance of sintered porous wicks for loop heat pipe, Exp. Therm. Fluid Sci. (2013). https://doi.org/10.1016/j.expthermflusci.2013 .04 .014 .

[10] N. Fathi, J. Kim, S. Jun, R.M. King, M. Amaya, S.M. You, Evaporative Cooling Heat Transfer of Water From Hierarchically Porous Aluminum Coating, Heat Transf. Eng. (2018). https://doi.org/10.1080/01457632.2017.1312 869.

[11] J.A. Weibel, S. V. Garimella, M.T. North, Characterization of evaporation and boiling from sintered powder wicks fed by capillary action, Int. J. Heat Mass Transf. (2010). https://doi.org/10.1016/j.ijheatmasstransfer.2 010.05.043.

[12] Y.T. Chen, S.W. Kang, Y.H. Hung, C.H. Huang, K.C. Chien, Feasibility study of an aluminum vapor chamber with radial grooved and sintered powders wick structures, Appl. Therm. Eng. (2013). https://doi.org/10.1016/j.applthermaleng.201 2.10.035.

[13] X. Ji, J. Xu, A.M. Abanda, Copper foam based vapor chamber for high heat flux dissipation, Exp. Therm. Fluid Sci. (2012). https://doi.org/10.1016/j.expthermflusci.2012 .02 .004 .

[14] Y. Li, W. Zhou, Z. Li, Z. Chen, Y. Gan,
Experimental analysis of thin vapor chamber with composite wick structure under different cooling conditions, Appl. Therm. Eng. (2019). https://doi.org/10.1016/j.applthermaleng.201 9.04.094.

[15] G. Huang, W. Liu, Y. Luo, Y. Li, H. Chen, Fabrication and thermal performance of mesh-type ultra-thin vapor chambers, Appl. Therm. Eng. (2019). https://doi.org/10.1016/j.applthermaleng.201 9.114263 .

[16] A.A.A. Attia, B.T.A. El-Assal, Experimental investigation of vapor chamber with different working fluids at different charge ratios, Ain Shams Eng. J. (2012). https://doi.org/10.1016/j.asej.2012.02.003.

[17] M. Wang, W. Cui, Y. Hou, Thermal spreading resistance of grooved vapor chamber heat spreader, Appl. Therm. Eng. (2019). https://doi.org/10.1016/j.applthermaleng.201 9.03.025.

[18] G.S. Hwang, Y. Nam, E. Fleming, P. Dussinger, Y.S. Ju, M. Kaviany, Multi-artery heat pipe spreader: Experiment, Int. J. Heat Mass Transf. (2010). https://doi.org/10.1016/j.ijheatmasstransfer.2 010.02.046.

[19] M.J. Gibbons, P. Di Marco, A.J. Robinson, Heat flux distribution beneath evaporating hydrophilic and superhydrophobic droplets, Int. J. Heat Mass Transf. 148 (2020) 119093.

[20] S.C. Wong, K.C. Hsieh, J. Da Wu, W.L. Han, A novel vapor chamber and its performance, Int. J. Heat Mass Transf. (2010). https://doi.org/10.1016/j.ijheatmasstransfer.2 010.02.001.

[21] Y.T. Chen, M. Miao, D.Y. Ning, T.F. Chu, W.E. Chen, Thermal performance of a vapor chamber heat pipe with diamond-copper composition wick structures, in: IMPACT Conf. 2009 Int. 3D IC Conf. - Proc., 2009. https://doi.org/10.1109/IMPACT.2009.53821 86.

[22] G. Hansen, E. Næss, Performance of compressed nickel foam wicks for flat vertical heat pipes, Appl. Therm. Eng. (2015). https://doi.org/10.1016/j.applthermaleng.201 5.02.040. 
[23] A.M. Gheitaghy, H. Saffari, M. Mohebbi, Investigation pool boiling heat transfer in Ushaped mesochannel with electrodeposited porous coating, Exp. Therm. Fluid Sci. (2016).

https://doi.org/10.1016/j.expthermflusci.2016 .03.011.

[24] Y. Chen, L.S. Melvin, S. Rodriguez, D. Bell, M.M. Weislogel, Capillary driven flow in micro scale surface structures, Microelectron. Eng. (2009). https://doi.org/10.1016/j.mee.2009.02.016.

[25] M. Sigurdson, Y. Liu, P. Bozorgi, D. Bothman, N. MacDonald, C. Meinhart, A large scale Titanium Thermal Ground Plane, Int. J. Heat Mass Transf. (2013). https://doi.org/10.1016/j.ijheatmasstransfer.2 013.01.064.

[26] S. Escobar, N. Kumari, R. Shih, S. Anthony, C. Bash, Liquid flow analysis in porous media for large vapor chamber with multiple heat sources, in: ASME 2015 Int. Tech. Conf. Exhib. Packag. Integr. Electron. Photonic Microsystems, InterPACK 2015, Collocated with ASME 2015 13th Int. Conf. Nanochannels, Microchannels, Minichannels, 2015. https://doi.org/10.1115/IPACK201548770.

[27] B. Liu, H. Li, K. Li, Q. Meng, C. Yang, C. Fu, Effects of Heat Source Positions on Temperature Uniformity of Large Vapor Chamber Antigravity Flat Plate Heat Pipe, Arab. J. Sci. Eng. (2019). https://doi.org/10.1007/s13369-018-03710-9.

[28] M. Gibbons, C. Feng, S. Chandra, Composite Heat Sink LED Cooling, (2018) 2-4. https://doi.org/10.25071/10315/35377.

[29] J.T. Yao, G.J. Yang, C.X. Li, C.J. Li, Fabrication of porous stainless steel by flame spraying of semimolten particles, Mater. Manuf. Process. (2014). https://doi.org/10.1080/10426914.2014.9414 79.

[30] R. Gonzalez, H. Ashrafizadeh, A. Lopera, P. Mertiny, A. McDonald, A Review of Thermal Spray Metallization of Polymer-Based Structures, J. Therm. Spray Technol. (2016). https://doi.org/10.1007/s11666-016-0415-7.
Capillary rise of liquids in thermally sprayed porous copper wicks, Exp. Therm. Fluid Sci. (2018).

https://doi.org/10.1016/j.expthermflusci.2018 .05 .031 .

[32] C. Feng, S. Chandra, Evaporation of ethanol films wicking on structured, porous coatings deposited on copper plates, Int. J. Heat Mass Transf.

(2019). https://doi.org/10.1016/j.ijheatmasstransfer.2 019.03.045.

[33] I.B. Butler, M.A.A. Schoonen, D.T. Rickard, Removal of dissolved oxygen from water: A comparison of four common techniques, Talanta. (1994). https://doi.org/10.1016/0039-9140(94)80110$\mathrm{X}$.

[34] T.L. Bergman, F.P. Incropera, A.S. Lavine, Fundamentals of heat and mass transfer, Wiley, 2011.

[35] McMaster-Carr, Multipurpose 110 Copper with Certification, (n.d.). https://www.mcmaster.com/1012n58 (accessed July 10, 2019).

[36] S. Lips, F. Lefèvre, J. Bonjour, Combined effects of the filling ratio and the vapour space thickness on the performance of a flat plate heat pipe, Int. J. Heat Mass Transf. (2010). https://doi.org/10.1016/j.ijheatmasstransfer.2 009.10.022.

[37] E. Orlova, D. Feoktistov, G. Kuznetsov, Investigation of drop dynamic contact angle on copper surface, in: EPJ Web Conf., 2015. https://doi.org/10.1051/epjconf/20158201053

[38] D.A. Reay, P.A. Kew, R.J. McGlen, Heat pipes Theory, Design and Applications, 2014. https://doi.org/http://dx.doi.org/10.1016/B97 8-0-08-098266-3.00005-4.

[39] L. Kirkup, R.B. Frenkel, An Introduction to Uncertainty in Measurement, 2006. https://doi.org/10.1017/cbo9780511755538.

[31] C. Feng, S. Yugeswaran, S. Chandra, 